\title{
Double carbonate of ammonia and magnesia
}

\section{M.P.A Favre}

To cite this article: M.P.A Favre (1844) Double carbonate of ammonia and magnesia, Philosophical Magazine Series 3, 24:161, 475-476, DOI: 10.1080/14786444408644900

To link to this article: http://dx.doi.org/10.1080/14786444408644900

曲 Published online: 30 Apr 2009.

Submit your article to this journal

Џ Article views: 3

Q View related articles $₫$ 
if the attention be momentarily directed to the appearance of the needle, its outline is seen to be indistinct, and those parts which re, flect most light are seen with luminous protuberances, exhibiting all the appearances of light imperfectly focalized on the retina. If the eye be kept directed to the needle for but a very short time (accompanied perhaps by an effort to see distinctly), the ill-defined image rapidly contracts to perfect vision.

Topsham, near Exeter, March 4, 1844.

\section{DOUBLE CARBONATE OF AMMONIA AND MAGNESIA. \\ BY M. P. A FAVRE.}

This salt may be obtained in several modes; by agitating carbonate of magnesia in a solution of carbonate of ammonia and filtration, the solution rapidly deposits crystals on the sides of the vessel containing it, and these are right rectangular prisms; when they are collected and spread on filtering paper, they dry rapidly; after being inclosed in a bottle, when perfectly dry, they did not yield any ammoniacal odour, on opening the bottle several days afterwards.

The portion remaining on the filter, again submitted to similar treatment, yielded a solution which afforded more crystals, and eventually it altogether assumed a granular aspect, and became entirely the salt in question, of which large quantities may be thus obtained. The analyses which were made of this salt were performed upon crystals which were deposited from the filtered liquor, and not those which granulated.

Another method for obtaining large quantities of these crystals, and in a very pure state, consists in mixing a saturated solution of bicarbonate of magnesia with one of carbonate of ammonia; the double carbonate of magnesia, being very slightly soluble, notwithstanding a great excess of carbonate of ammonia, but few crystals are obtained by the first method above described; whereas the bicarbonate of magnesia being more soluble, brilliant and well-defined crystals of the double carbonate are obtained in a few seconds after it is mixed with the solution of carbonate of ammonia.

This salt in fine prismatic crystals yielded by analysis as under :-

$$
\begin{aligned}
& \begin{array}{llll}
\text { Magnesia . . . . } & 15 \cdot 77 & \mathbf{1 5} \cdot 92 & 15.8
\end{array} \\
& \text { Carbonic acid .. } 34.90 \quad 35.00 \quad \text {... } \\
& \begin{array}{rrrr}
\text { Hydrogen . . . . . } 6.70 & 6.70 & \ldots & \ldots
\end{array} \\
& \begin{array}{llll}
\text { Azote........... } & 11.60 & \ldots & \ldots \\
\text { Oxygen } . . . \cdots & \frac{31.03}{100^{\circ}} & \ldots & \ldots
\end{array}
\end{aligned}
$$

These analyses indicate the annexed formula :

$$
\text { ( } \mathrm{CO}^{2}, \mathrm{MgO}, \mathrm{CO}^{2} \mathrm{H}^{4} \mathrm{AzO}, 4 \mathrm{HQ} \text { ), }
$$

which gives the following numbers:-

$$
\begin{aligned}
& \text { Magnesia ....... } 16 \cdot 28 \\
& \text { Carbonic acid .... } 34 \cdot 70 \\
& \text { Hydrogen ....... 6. 6.31 } \\
& \text { Azote ........ 11.17 } \\
& \text { Oxygen .......... } \frac{31 \cdot 54}{100^{\circ}}
\end{aligned}
$$


This salt is unalterable by exposure to the air; when treated with cold water the crystals lose their transparency, but nearly retain their form.-Ann. de Ch. et de Phys., Avril 1844.

\section{ON THE IDENTITY OF SCORODITE AND NÉOCTĖSE. BX M. DAMOUR.}

M. Descloizeau having found that these substances agreed perfectly in their primary form, viz, a right rhombic prism, and in the various modifications to which it is subject, M. Damour undertook a. fresh analysis of them, that of Berzelius not agreeing with the previous one of Ficinus. For this purpose crystals of scorodite from Vaulry (Haute Vienne), from Saxony and Cornwall, and of the néoctèse of Brazil, from the collection of the Ecole des Mines, were examined.

The specific gravity of scorodite of Vautry was found to be $3 \cdot 11$, and that of the néoctèse of Brazil 3.18; when heated in a tube both of them yielded water, which did not alter litmus paper; the residual matter was opake and of a grayish-yellow colour; no arsenious acid sublimed when pure crystals were operated on; before the blowpipe both substances swell up and are reduced to blackish-gray globules; on charcoal they yield arsenical odour, and a black scoria which obeys the magnet. Nitric acid, whether hot or cold, does not act upon scorodite or néoctèse, but hydrochloric acid readily dissolves them, and the solution is of a brown colour; this is decomposed by ammonia, partially; the precipitate formed is of a brown colour.

The powder of these minerals when placed on a fragment of caustic potash, instantly assumes a rust colour, without any admixture of blackness; the hydrochloric solution, mixed with the chloride of sodium and gold, gives no trace of reduced gold. These experiments prove that the minerals in question are of the same nature, and that the oxide of iron which they contain is the peroxide; in order to determine the proportions of the constituents of these minerals the following experiments were performed:-

The mineral, reduced to powder and dried in vacuo at the usual temperature, was dissolved, with heat, in concentrated hydrochloric acid; the solution took place rapidly. The liquor was diluted with water and dropped gradually into a phial containing ammonia and hydrosulphate of ammonia. The mixture was digested at a temperature of $122^{\circ}$ to $140^{\circ} \mathrm{Fahr}$, and at the expiration of twenty-four hours, the precipitated sulphuret of iron formed was collected on a filter and properly washed (A.). The sulphuret of iron, while moist, was dissolved in aqua regia, and then precipitated by means of ammonia; the liquor (A.) separated from the sulphuret of iron was rendered slightly acid by acetic acid, and after some time yellow sulphuret of arsenic was precipitated; in order to ascertain the proportion of arsenic which it contained, this sulphuret, previously dried in vacuo, was acted on by aqua regia; globules of sulphur remained, which were collected and weighed ; the acid liquor contained arsenic and a little sulphuric acid formed from the sulphur, the quantity of 